Article

\title{
Preparation of Solid Fuel Hydrochar over Hydrothermal Carbonization of Red Jujube Branch
}

\author{
Zhiyu Li ${ }^{1,2}{ }^{\circledR}$, Weiming $\mathrm{Yi}^{1}{ }^{1} *$, Zhihe Li ${ }^{1}$, Chunyan Tian ${ }^{1}$, Peng Fu ${ }^{1}$, Yuchun Zhang ${ }^{1}$, \\ Ling Zhou ${ }^{3, *}$ and Jie Teng ${ }^{4, *}$ \\ 1 School of Agricultural Engineering and Food Science, Shandong University of Technology, \\ Zibo 255000, China; lizhiyu@sdut.edu.cn (Z.L.); lizhihe@sdut.edu.cn (Z.L.); tiancy@sdut.edu.cn (C.T.); \\ fupsklcc@126.com (P.F.); zhangyc@sdut.edu.cn (Y.Z.) \\ 2 Key Laboratory of Modern Agricultural Engineering, Department of Education of Xinjiang Uygur \\ Autonomous Region, Alar 843300, China \\ 3 College of Mechanic and Electrical Engineering, Tarim University, Alar 843300, China \\ 4 School of Agricultural Sciences, Jiangxi Agricultural University, Nanchang 330045, China \\ * Correspondence: yiweiming@sdut.edu.cn (W.Y.); zhoul-007@163.com (L.Z.); tengjie33@163.com (J.T.); \\ Tel.: +86-0533-2786-398 (W.Y.); +86-0997-4683-855 (L.Z.); +86-0791-8381-3185 (J.T.)
}

Received: 26 November 2019; Accepted: 14 January 2020; Published: 18 January 2020

\begin{abstract}
Biomass energy is becoming increasingly important, owing to the decreasing supply of fossil fuels and growing environmental problems. Hydrothermal carbonization (HTC) is a promising technology for producing solid biofuels from agricultural and forestry residues because of its lower fossil-fuel consumption. In this study, HTC was used to upgrade red jujube branch (RJB) to prepare hydrochar at six temperatures $\left(220,240,260,280,300\right.$, and $\left.320^{\circ} \mathrm{C}\right)$ for $120 \mathrm{~min}$, and at $300^{\circ} \mathrm{C}$ for 30 , 60,90 , and $120 \mathrm{~min}$. The results showed that the energy recovery efficiency (ERE) reached maximum values of $80.42 \%$ and $79.86 \%$ at a residence time of $90 \mathrm{~min}$ and a reaction temperature of $220{ }^{\circ} \mathrm{C}$, respectively. X-ray diffraction results and Fourier transform infrared spectroscopy measurements show that the microcrystal features of RJB were destroyed, whereas the hydrochar contained an amorphous structure and mainly lignin fractions at increased temperatures. Thermogravimetric analysis shows that the hydrochar had better fuel qualities than RJB, making hydrochar easier to burn.
\end{abstract}

Keywords: red jujube branch; hydrothermal carbonization; hydrochar; energy recovery efficiency; solid fuel

\section{Introduction}

Fossil-fuel combustion increases $\mathrm{CO}_{2}$ emissions, leading to global warming. The development of renewable energies, such as biomass energy, has the potential to reduce the global dependence on fossil fuels [1]. With the development of the Xinjiang jujube industry in China, the output of red jujube branch (RJB) exceeded 1.9 million tons in 2012. RJB is the by-product of the development of the jujube industry. It has a high lignocellulose content, which is an excellent renewable biological resource. However, biomass disposal has become a contentious issue. When hydrochar is used as a solid fuel, it helps reduce $\mathrm{NO}_{x}$ emissions during the combustion of conventional energy sources [2]. Recently, hydrothermal carbonization (HTC) has helped increase bio-energy production efficiency, and HTC has received attention owing to its ability to convert organic waste into solid fuel [3-5]. The pathway to convert agricultural and forestry residues into solid fuels may be a viable RJB treatment method for reducing environmental pollution from RJB, while also providing new energy sources [6].

Compared with the biomass treatment technology of pyrolysis and combustion, HTC has the advantages of low energy input and mild reaction conditions [7]. Therefore, HTC is a good approach to convert biomass feedstocks to upgraded solid products or high-performance fuels. RJB has great 
potential as a raw material for the production of hydrochar [8]. Thus far, although RJB is a typical biomass in northwestern China, there have been few studies on the HTC of RJB for hydrochar production. Hydrochar can specifically be used as a solid fuel, activated carbon, and in other such applications. Presently, many studies focus on the HTC of other biomass [9-12].

In this study, the effects of modifying the reaction conditions of HTC on hydrochar production was examined. The results were analyzed to comprehensively evaluate the effect of temperature and time on product characteristics. The main objectives of this study are: (1) to report on the study of the structural and morphological properties of the hydrochar; (2) discuss the investigation of the combustion behavior of the hydrochar; and (3) report on the study of the fuel properties and combustion performance, as well as the evaluation of the optimal reaction conditions for the preparation of the hydrochar. The research results of RJB can provide readers with a deeper understanding of the HTC of RJB to prepare the hydrochar and provide a theoretical basis for the energy utilization of RJB. In terms of the efficient utilization of energy, the HTC of RJB seems to be a viable pathway.

\section{Materials and Methods}

\subsection{Materials}

The RJB used in the experiment was sourced from Alar City, Xinjiang Uygur Uyghur Autonomous Region. The industrial analysis of the red jujube branch is shown in Table 1.

Table 1. The physical and chemical properties of red jujube branch (RJB).

\begin{tabular}{cccccc}
\hline \multirow{2}{*}{ Sample } & \multirow{2}{*}{ Moisture (\%) } & \multicolumn{3}{c}{ Proximate Analysis (\%) } & \multirow{2}{*}{ Heating Value (MJ kg $\mathbf{~ k}^{\mathbf{- 1})}$} \\
\cline { 3 - 5 } & & Fixed Carbon & Volatile Matter & Ash & \\
\hline RJB & 8.85 & 17.91 & 73.57 & 2.5 & 19.06 \\
\hline
\end{tabular}

\subsection{HTC Experiment}

HTC was conducted in a laboratory-scale $500-\mathrm{mL}$ high-pressure reactor using a magnetic stirrer (Parr 4575HP/HT, USA). The reactants were mixed to form a slurry, with RJB and distilled water at a ratio of 1:10 $(w / v)$. The sample was stirred at a rate of $300 \mathrm{rpm}$ throughput the experiment using a magnetic actuator with constant torque. Meanwhile, the heating rate was set at $10^{\circ} \mathrm{C} / \mathrm{min}$. Then, the autoclave was pressurized to $4.0 \mathrm{MPa}$ with nitrogen. The slurry used in each experiment was weighed and then poured into the reactor. The reactor was then sealed with a reactor cover and purged with nitrogen to remove the air. The control system was then turned on to set the temperature required for the reaction. The temperature inside the reactor was monitored continuously. The reaction residence time was calculated based on the instant the temperature of the reactor reached the required value. The effect of the reaction temperatures of $220,240,260,280,300$, and $320^{\circ} \mathrm{C}$ on the HTC of RJB was studied at a residence time of $120 \mathrm{~min}$. In addition, the effect of the residence times of 30,60, 90, and $120 \mathrm{~min}$ on the HTC of RJB was investigated at a reaction temperature of $300^{\circ} \mathrm{C}$. The control system was shut down after completion of each HTC experiment. After the reactor was rapidly cooled, the reactor cover was opened, and the reaction product was collected in a beaker. Finally, the weight of the collected product was recorded. The solid product was separated from the process water using a vacuum suction filter. The weights of the separated solid and liquid products were recorded. The solid and liquid yields were calculated using the ratio of the weight of the solid and liquid products, respectively, to the initial weight of the raw slurry. The gas yield was calculated using the difference [13]. Each test was conducted three times, and the average of the three tests was used as the test value. The energy recovery efficiency (ERE) was calculated as the ratio of the calorific value of dry hydrochar and raw materials to the mass yield.

$$
\text { Solid yield }=\frac{\text { Weight of solid after filtration }}{\text { Weight of raw slurry }}
$$




$$
\begin{gathered}
\text { Liquid yield }=\frac{\text { Weight of liquid after filtration }}{\text { Weight of raw slurry }} \\
\text { Mass yield }=\frac{\text { Weight of dry matter in hydrochar }}{\text { Weight of dry solid matter in raw material }} \\
\text { Energy recovery efficiency }=\frac{\text { Calorific value of hydrochar }}{\text { Calorific value of raw material }} \times \text { Mass yield }
\end{gathered}
$$

\subsection{Analytical Method}

A powder sample with a particle size of $250 \mu \mathrm{m}$ was prepared by sieving for testing. Proximate testing was performed on a YX-GYFX 7701 automatic industrial analyzer. The higher heating values of the sample were measured by a YX-ZR bomb calorimeter. The Fourier transform infrared spectroscopy (FT-IR) test of the sample was performed using a Thermo Fisher Nicolet iS10 FT-IR spectrometer. The tableting sample was prepared using dry potassium bromide to reduce the interference of water. Spectrum data were recorded over a wavenumber range of 4000 to $400 \mathrm{~cm}^{-1}$ at a resolution of $4 \mathrm{~cm}^{-1}$. Thermogravimetric analysis (TGA) of RJB and hydrochar was performed using an STA 449 F5 Jupiter ${ }^{\circledR}$ thermogravimetric analyzer. The data of the mass loss and mass loss rate of the sample were obtained under the analysis conditions shown in Table 2.

Table 2. Operating conditions for TGA.

\begin{tabular}{cc}
\hline TGA Conditions & Value \\
\hline Sample weight & $8 \mathrm{mg}$ \\
Heating rate & $10{ }^{\circ} \mathrm{C} \mathrm{min}$ \\
Atmosphere & Air \\
Gas flow rate & $30 \mathrm{~mL} \mathrm{~min}^{-1}$ \\
Starting temperature & $30^{\circ} \mathrm{C}$ \\
Final holding temperature & $800^{\circ} \mathrm{C}$ \\
\hline
\end{tabular}

\section{Results and Discussion}

\subsection{Product Distribution}

The effect of residence time on the three-state yield was studied. The three-state yield results are shown in Figure 1a-c. From 30 to 120 min, the solid yield showed an upward trend; however, both the liquid and gas yields showed downward trends. When the residence time reached $120 \mathrm{~min}$, the solid yield reached a maximum value of $23.42 \%$. The increase in residence time is mainly due to the decrease in solid yield. In the experimental group, longer residence times may allow more time for the hydrothermal reaction, resulting in an increased pore structure of hydrochar and the adsorption of more liquid, which may be the reason for the increase in the solid yield [13,14]. 


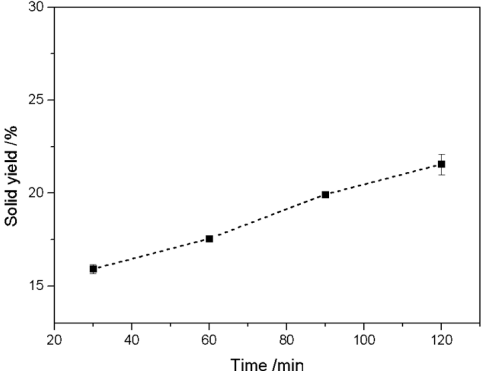

(a)

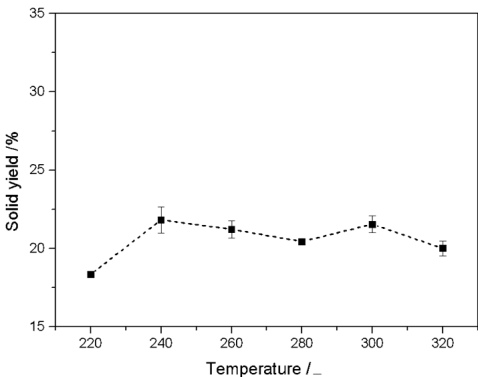

(d)

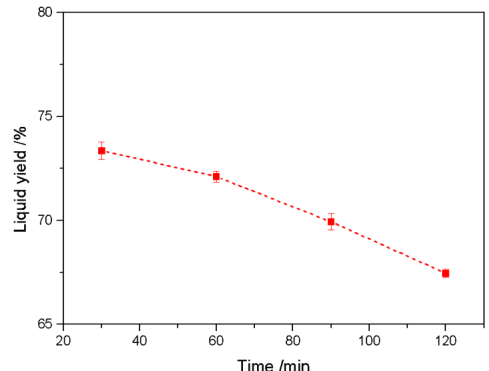

(b)

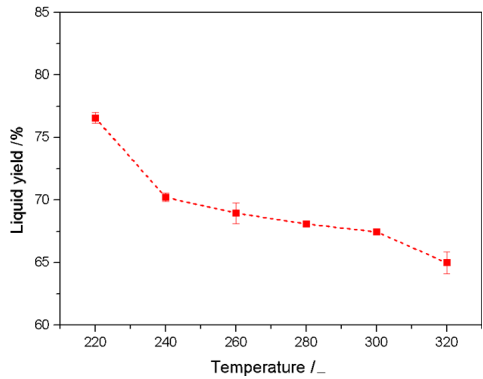

(e)

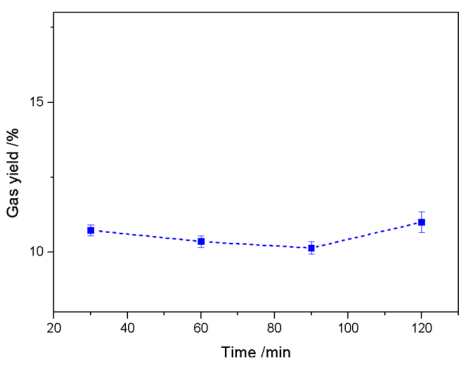

(c)

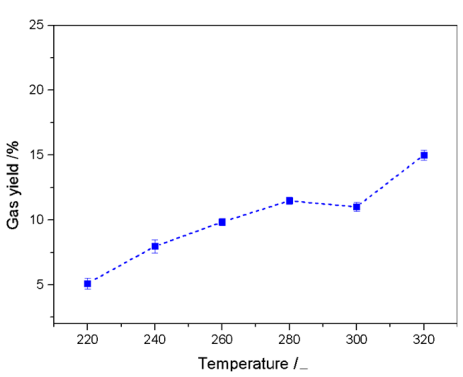

$(\mathbf{f})$

Figure 1. Effect of residence time $\left(300^{\circ} \mathrm{C}\right)$ and reaction temperature $(120 \mathrm{~min})$ on the yield of solid, liquid, and gas. (a) Solid yield; (b) liquid yield; (c) gas yield; (d) solid yield; (e) liquid yield; (f) gas yield.

Numerous studies have evaluated the HTC of RJB. Heilmann et al. studied the HTC of distiller's grains at an initial reaction pressure of $1.72 \mathrm{MPa}$. The results showed that the highest hydrochar yield was $45.6 \%$ at a temperature of $190{ }^{\circ} \mathrm{C}$ and residence time of $2 \mathrm{~h}$. The lowest hydrochar yield was $30.2 \%$ at a temperature of $210{ }^{\circ} \mathrm{C}$ and residence time of $0.5 \mathrm{~h}$ [15]. Elaigwu et al. investigated the HTC of lignocellulosic waste material at a reaction pressure of $1.80 \mathrm{MPa}$. The results showed that the highest hydrochar yield was $37.87 \%$ at a temperature of $200{ }^{\circ} \mathrm{C}$ and residence time of $2 \mathrm{~h}$. The lowest hydrochar yield was $30.6 \%$ at a temperature of $200{ }^{\circ} \mathrm{C}$ and residence time of $20 \mathrm{~min}$ [16]. The yield of our study was lower than those of reports, which is mainly attributed to the following three reasons. First, within the investigated parameters, longer residence times resulted in more complete carbonization, and consequently lower hydrochar yields [17]. Second, the reaction temperature significantly affected the physicochemical properties of the water (subcritical water) in the HTC process. The density of water changed up to one order of magnitude depending upon the temperature $\left(0-350{ }^{\circ} \mathrm{C}\right)$, which allowed easier penetration of water in porous media and resulted in enhanced decomposition of the biomass [18]. Finally, oxygen was lost during the liquefaction reactions, which are parallel reactions to the hydrothermal process of the biomass [16].

The reaction temperature affected the HTC. The three-state yield results are shown in Figure 1b-f. With the increase in reaction temperature, the solid yield first increased, then decreased, and finally stabilized. With the increase in temperature from 220 to $320^{\circ} \mathrm{C}$, the liquid and gas yields showed downwards and upwards trends, respectively. The solid yield reached a maximum value of $21.82 \%$ at the reaction temperature of $240^{\circ} \mathrm{C}$; this may be due to the higher temperature causing the raw material to further decompose into a liquid phase, resulting in a lower solid yield. The reaction temperature, residence time, and material properties are the main factors in the HTC process [14].

\subsection{Energy Recovery Efficiency}

Energy was used in the HTC process to improve the fuel properties of the products [15]. Figure 2 shows the hydrochar ERE and heating value results. Therefore, the HTC process was evaluated by ERE, which was affected by the reduced product yield and increased heating value (Figures 1 and 2) [19]. The ERE of hydrochar after residence time treatment is shown in Figure 2a. The ERE trend is inconsistent 
with the solid yield over time. The ERE first increased and then decreased with increasing residence time. The ERE reached a maximum value of $80.42 \%$ for a residence time of $90 \mathrm{~min}$.

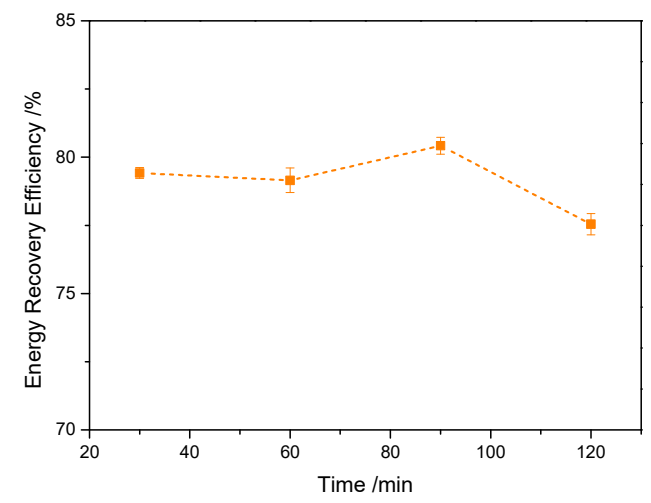

(a)

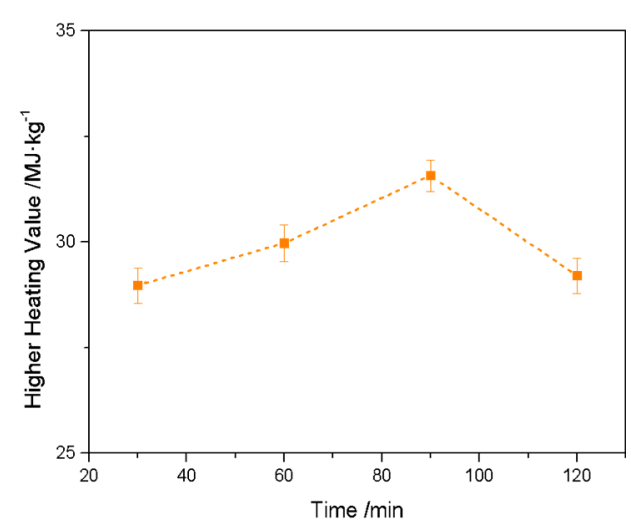

(c)

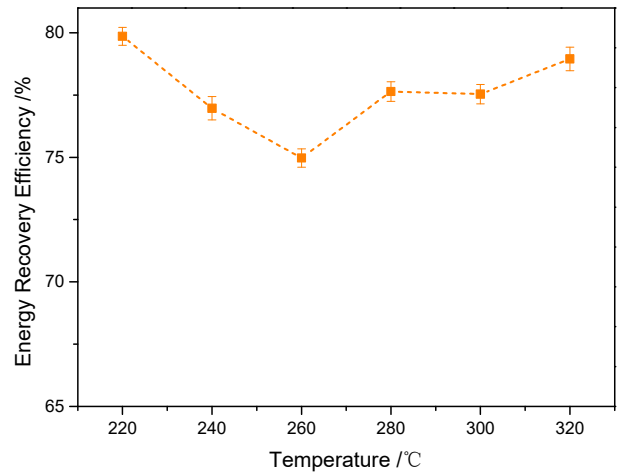

(b)

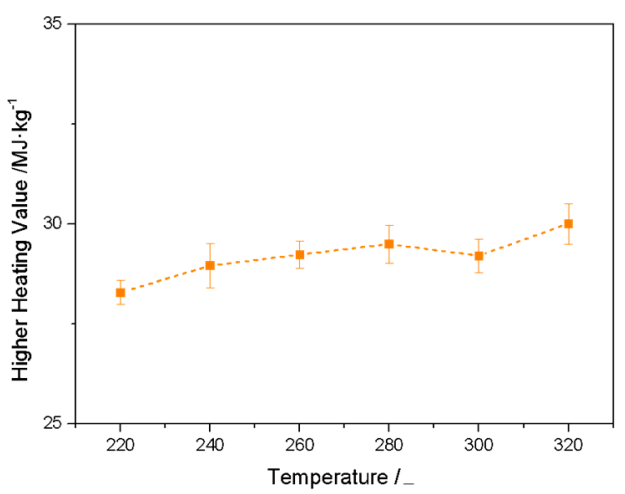

(d)

Figure 2. Energy recovery efficiency and higher heating value of hydrochar after hydrothermal carbonization (HTC) treatment (residence time $\left(300^{\circ} \mathrm{C}\right)$ and reaction temperature $(120 \mathrm{~min})$. (a) Residence time; (b) reaction temperature; (c) residence time; (d) reaction temperature.

As shown in Figure 2b, the effect of reaction temperature on ERE was studied. In contrast to the solid yield, the ERE was inconsistent with the reaction temperature. The ERE decreased and then increased with increasing reaction temperature. The ERE reached a maximum of $79.86 \%$ for the reaction temperature of $220{ }^{\circ} \mathrm{C}$ during the HTC process because the decarboxylation and dehydration reactions increased the temperature $[19,20]$. For lignocellulosic biomass, ERE generally decreased with increasing reaction temperature, which is consistent with the findings of Kambo [21].

The heating value of hydrochar increased with increasing reaction temperature. In addition, the solid yield was reduced owing to a decrease in the volatile-matter content caused by chemical dehydration and decarboxylation reactions (i.e., excluding $\left.\mathrm{CO}_{2}\right)[19,22,23]$.

Therefore, the maximum ERE can be obtained under optimal temperature conditions during HTC [24-27]. ERE is an important factor in evaluating the production of hydrochar by HTC. The highest ERE is used to represent the optimum reaction temperature during HTC [28].

The effect of residence time and reaction temperature on the heating value of hydrochar is shown in Figure 2c,d. The results indicate that the heating value of hydrochar follows the order $90 \mathrm{~min}>$ $60 \mathrm{~min}>120 \mathrm{~min}>30 \mathrm{~min}$, and the highest heating value is $31.57 \mathrm{MJ} \mathrm{kg}^{-1}$. For identical treatment temperatures, the heating value of hydrochar increased with increasing residence time, but the heating value decreased more than $90 \mathrm{~min}$. It is possible that the residence time was too long, which lead to an increase in the ash content and a decrease in the volatile content of the hydrochar. The heating value of hydrochar followed the order $320^{\circ} \mathrm{C}>280^{\circ} \mathrm{C}>260^{\circ} \mathrm{C}>300^{\circ} \mathrm{C}>240{ }^{\circ} \mathrm{C}>220^{\circ} \mathrm{C}$, and the 
highest heating value was $30.00 \mathrm{MJ} \mathrm{kg}^{-1}$. Similarly, for identical residence times, as the treatment temperature increased, the degree of removal of water or oxygen in the organic matter increased, resulting in an increase in the heating value of the hydrochar. The result shows that the optimum HTC temperature produced energy-rich solid fuels. Because lignin is the most abundant compound in RJB, HTC improves the heating value of lignin and the solid yield.

\subsection{Characterization of RJB and Hydrochar}

As shown in Figure $3 a$, the test results of the hydrochar obtained from the residence time and RJB contain broad peaks between $10^{\circ}$ and $30^{\circ}$, which may be due to the diffraction of amorphous carbon $[27,29]$. This suggests that the RJB was carbonized. There are two crystalline peaks on RJB, which are the cellulosic peaks at $22.7^{\circ}$ and $30.36^{\circ}$, respectively [30]. However, hydrochar has no crystalline peak at $30.36^{\circ}$, which may be due to the fact that hydrochar contained mainly amorphous components [31]. The results indicate that the crystalline structure of hydrochar was destroyed.

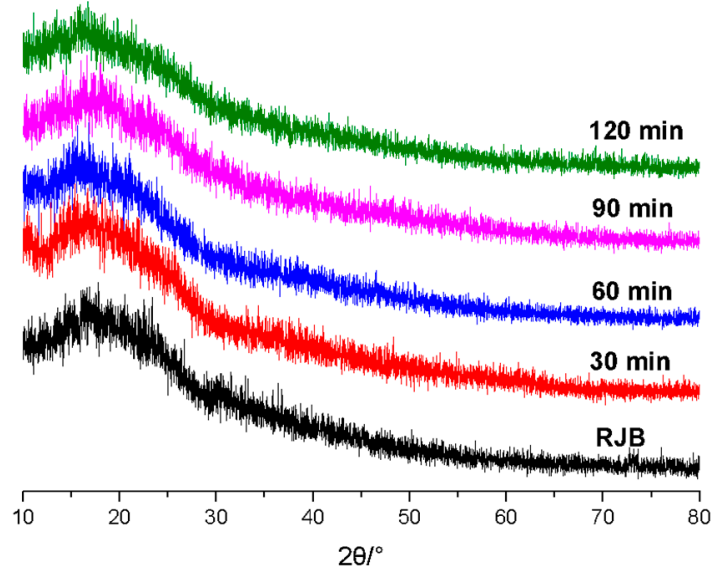

(a)

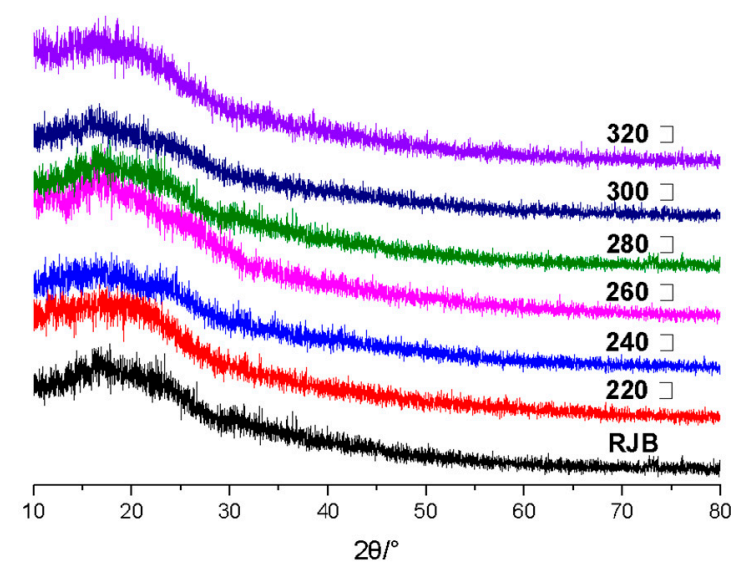

(b)

Figure 3. XRD spectra for RJB and hydrochar produced by HTC. (a) Residence time; (b) reaction temperature.

The XRD patterns for hydrochar obtained from the reaction temperature and RJB were compared, as shown in Figure $3 \mathrm{~b}$. There are two sharply crystalline cellulosic peaks from the cellulose crystal structure of RJB at $22.7^{\circ}$ and $30.36^{\circ}$; however, there is no peak at $30.36^{\circ}$ in the hydrochar, indicating that it contained mainly amorphous components. The decomposition of cellulose in RJB occurred during HTC, which realized the transformation of hydrochar from a microcrystalline structure to a non-crystalline structure. The main component of the hydrochar product obtained by HTC was lignin, which has an amorphous structure [32].

The FT-IR spectra of RJB and hydrochar are shown in Figure 4. The FT-IR spectra of hydrochar obtained from the residence time and reaction temperature are similar, differing only in the intensity of some peaks. The FT-IR spectrum of hydrochar was similar in part to that of RJB. The FT-IR spectra indicated that all samples contained an $-\mathrm{OH}$ functional group at $3500-3300 \mathrm{~cm}^{-1}$. 


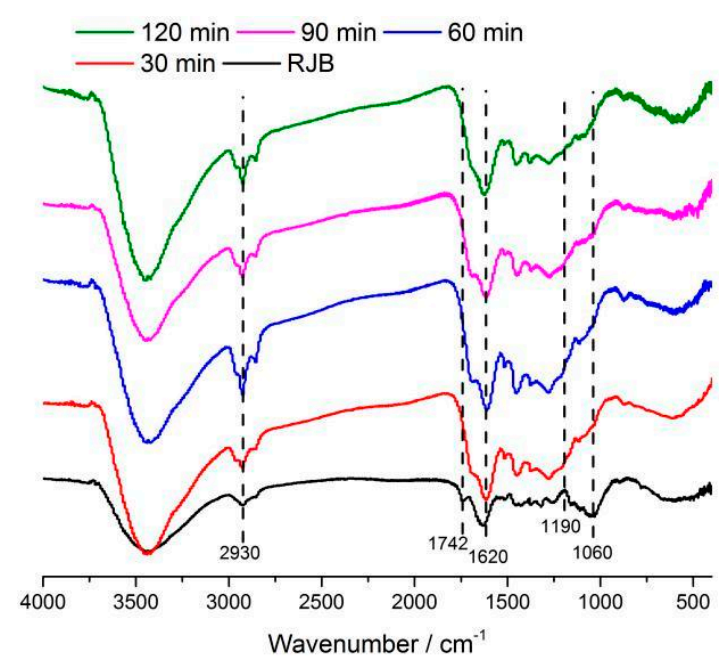

(a)

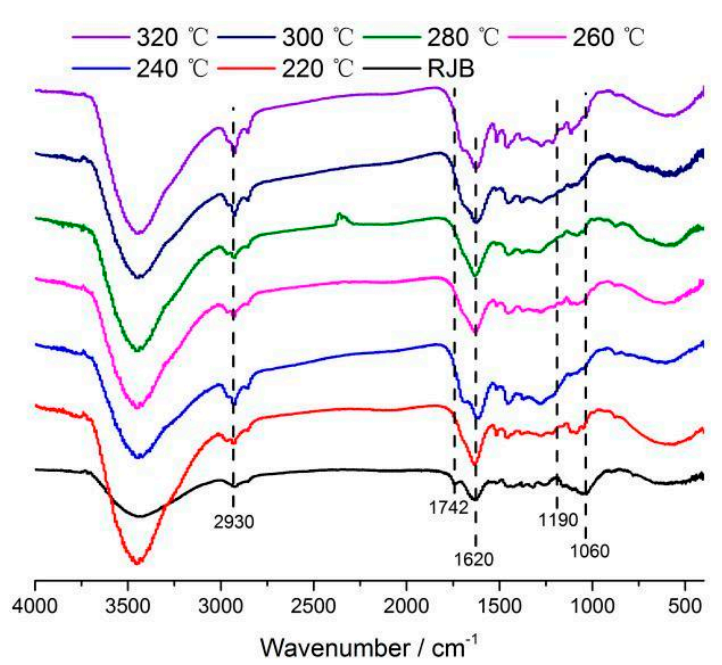

(b)

Figure 4. FT-IR spectra of RJB and its derived hydrochars. (a) Residence time; (b) reaction temperature.

The peak intensity exhibits no clear changes with increasing residence time (or reaction temperature), which confirms that $-\mathrm{OH}$ was not decomposed during $\mathrm{HTC}$, as shown in Figure 4a or Figure $4 \mathrm{~b}$. The $\mathrm{C}-\mathrm{H}$ stretching vibration at $3000-2800 \mathrm{~cm}^{-1}$ was attributed to either $-\mathrm{CH}_{2}$ or $-\mathrm{CH}_{3}$ functional groups, and the intensity of the peak indicates the presence of an aliphatic compound in the hydrochar.

The stretching vibration peak of aliphatic $\mathrm{C}-\mathrm{H}$ obtained from the hydrochar tended to increase with residence time from 30 to $120 \mathrm{~min}$ (or from 220 to $320^{\circ} \mathrm{C}$; see Figure 4b), as shown in Figure 4a [33]. The peak at $1742 \mathrm{~cm}^{-1}$ is derived from the ester $\mathrm{C}=\mathrm{O}$ stretching vibration of hemicelluloses and lignin [34].

The ester carbonyl group of the spectrum of RJB at $1734 \mathrm{~cm}^{-1}$ disappeared completely in the hydrochar, which may be because of the decomposition under hydrothermal conditions, including residence time or reaction temperature $[35,36]$. The peaks of RJB and all hydrochars around $1620 \mathrm{~cm}^{-1}$ correspond to the stretching vibration of the $\mathrm{C}=\mathrm{C}$ of the aromatic groups in lignin [20], confirming the stability of the aromatic structure of lignin [33]. This indicates that lignin does not completely decompose under hydrothermal conditions [37].

D-xylose and cellulose have a C-O stretching vibration peak at 1000-1200 $\mathrm{cm}^{-1}$, which means that there was either an ether bond or a methoxy group [20,37]. This -O peak decreased or disappeared with gradually increasing residence time (or reaction temperature), which may be attributed to the decomposition of carboxyl groups during the HTC process [20,31,37]. In addition, previous studies have shown that the C-O peak does not exist in the hydrochar components after HTC $[20,33]$.

\subsection{Combustion Behavior of Hydrochar}

The thermogravimetry (TG) and derivative thermogravimetry (DTG) profiles of RJB hydrochar at different hydrothermal temperatures are shown in Figure 5. Most of the hydrochars (except the raw material) had a mass loss of more than $91 \%$ between 250 and $540{ }^{\circ} \mathrm{C}$, and these hydrochars remained relatively stable below $250{ }^{\circ} \mathrm{C}$. The raw material had a mass loss of $90 \%$ in the range of 200 to $550{ }^{\circ} \mathrm{C}$. The maximum mass loss of the hydrochar occurred at approximately $460{ }^{\circ} \mathrm{C}$, whereas the maximum mass loss of the raw material occurred at $319^{\circ} \mathrm{C}$. The results show that the weight-loss temperature of hydrochar moved to the high temperature zone after HTC, and HTC reduced the temperature range of the combustion zone. This is because the hydrothermal reaction destroys the original structure of the biomass, allowing some of the volatile components to dissolve in the water, producing a more stable 
aromatic carbon. In addition, the burnout temperature of the hydrochar is lower than that of the raw material, making the hydrochar easier to burn out, which is beneficial for use as a fuel [37].

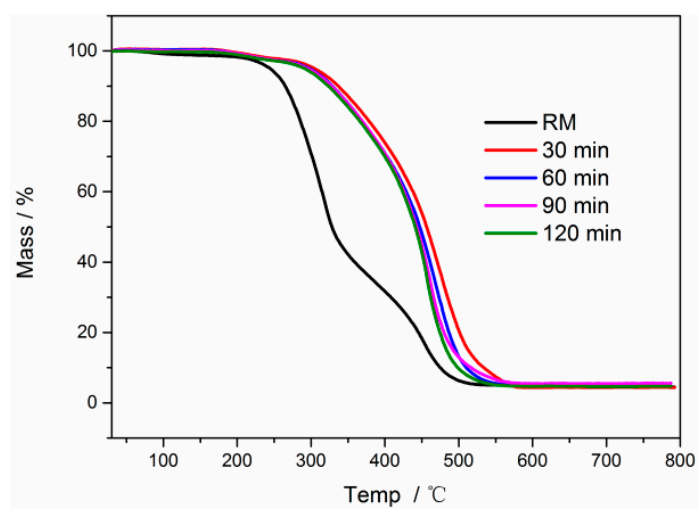

(a)

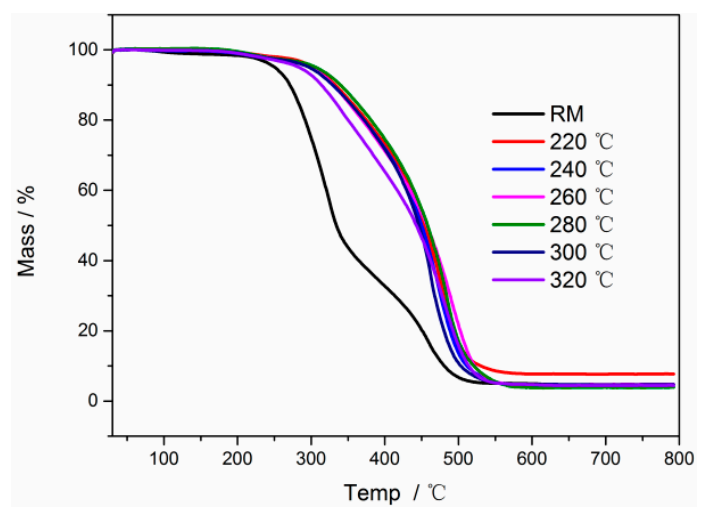

(c)

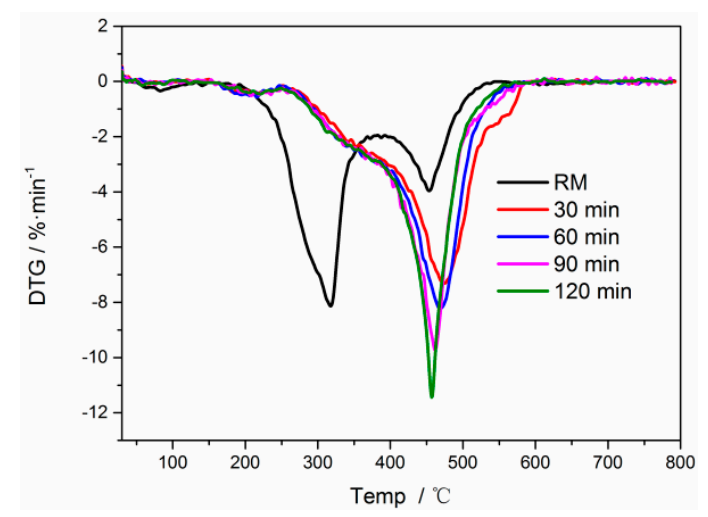

(b)

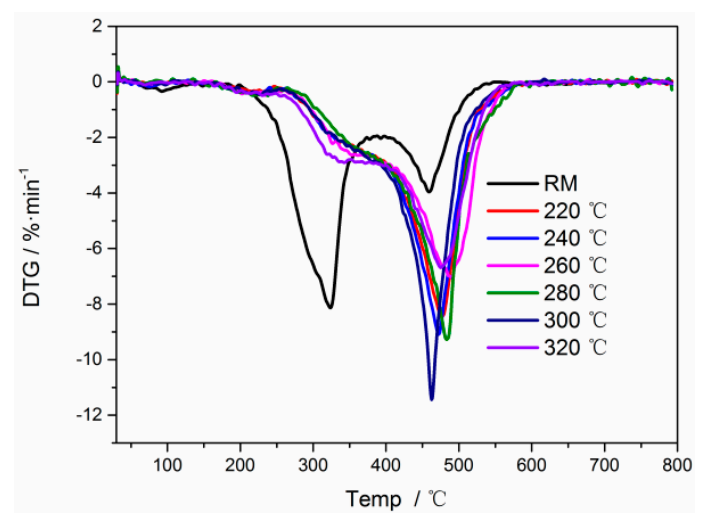

(d)

Figure 5. TGA of red jujube branch hydrochar. (a) TG of residence time; (b) derivative thermogravimetry (DTG) of residence time; (c) TG of reaction temperature; (d) DTG of reaction temperature. Note: The raw material is abbreviated as RM.

According to the peak of the remaining mass of the TG and the DTG curve, the thermostability of the treatment group was better than that of the raw material. The thermal stability increased with increasing residence time and reaction temperature. This may be because the volatile matter was reduced, and the fixed carbon was enhanced at higher temperature and longer residence times; these are the main factors affecting thermal stability [30]. HTC can cause many cracks in the hydrochar structures (Figure 5). Therefore, the combustion temperature of hydrochar is more concentrated [28].

The raw material is referred to as RM.

\section{Conclusions}

The fuel qualities of the produced hydrochars were evaluated by ERE. The results confirmed that RJB can produce hydrochar products with a higher ERE than RJB by HTC. ERE also increases with the increase in the severity of HTC reactions (longer time and higher temperature). Studies have found that the ERE of the hydrochar increased at higher reaction temperatures; however, most can be achieved at moderate temperatures. The experimental results showed that the ERE reached maximum values of $80.42 \%$ and $79.86 \%$ at a residence time of $90 \mathrm{~min}$ and a reaction temperature of $220^{\circ} \mathrm{C}$, respectively. The FT-IR and XRD measurements were used to obtain information about the chemical structure and thermal properties of the related hydrochar. The results showed that the microcrystal features of RJB were destroyed, and the hydrochar contained an amorphous structure and mainly lignin fractions at 
increased temperatures. TGA showed that the hydrochar has better fuel qualities than the RJB. For example, the burnout temperature and combustion temperature range of hydrochar decreased, making hydrochar easier to burn.

Author Contributions: Conceptualization, Z.L. (Zhiyu Li), W.Y., and J.T.; methodology, Z.L. (Zhiyu Li), Z.L. (Zhihe Li), and J.T.; validation, Z.L. (Zhiyu Li) and J.T.; experiment, Z.L. (Zhiyu Li), C.T., P.F., and Y.Z.; resources, L.Z.; writing-original draft preparation, Z.L. (Zhiyu Li), Z.L. (Zhihe Li), and L.Z.; writing and editing, W.Y., C.T., Z.L. (Zhihe Li), Y.Z., and J.T., and all authors reviewed the article. All authors have read and agreed to the published version of the manuscript.

Funding: This research was supported by the National Natural Science Foundation of China, China (Nos. 51536009), Taishan Scholars Program of Shandong Province, Ph.D. Program of Shandong University of Technology (4041-418033), and the National Natural Science Foundation of China (No. 41601601, 61501249), Open Project of Xinjiang Key Laboratory of Modern Agricultural Engineering (TDNG2020104), Scientific and Technological Research Projects in Key Fields of Xinjiang Production and Construction Corps (2019AB028), Youth Innovation Support Program of Shandong Colleges and Universities (2019KJD013).

Conflicts of Interest: The authors declare no conflict of interest.

\section{References}

1. Lynam, J.G.; Reza, M.T.; Yan, W.; Vásquez, V.R.; Coronella, C.J. Hydrothermal carbonization of various lignocellulosic biomass. Biomass Convers. Biorefinery 2015, 5, 173-181. [CrossRef]

2. Zheng, C.; Ma, X.; Yao, Z.; Chen, X. The properties and combustion behaviors of hydrochars derived from co-hydrothermal carbonization of sewage sludge and food waste. Bioresour. Technol. 2019, 285, 121347. [CrossRef] [PubMed]

3. Lucian, M.; Fiori, L. Hydrothermal carbonization of waste biomass: Process design, modeling, energy efficiency and cost analysis. Energies 2017, 10, 211. [CrossRef]

4. Basso, D.; Patuzzi, F.; Castello, D.; Baratieri, M.; Rada, E.C.; Weiss-Hortala, E.; Fiori, L. Agro-industrial waste to solid biofuel through hydrothermal carbonization. Waste Manag. 2016, 47, 114-121. [CrossRef]

5. Song, E.; Park, S.; Kim, H. Upgrading hydrothermal carbonization (HTC) hydrochar from sewage sludge. Energies 2019, 12, 2383. [CrossRef]

6. Laginhas, C.; Nabais, J.M.V.; Titirici, M.M. Activated carbons with high nitrogen content by a combination of hydrothermal carbonization with activation. Microporous. Mesoporous. Mater. 2016, 226, 125-132. [CrossRef]

7. Lin, Y.; Ma, X.; Peng, X.; Yu, Z. A mechanism study on hydrothermal carbonization of waste textile. Energy Fuels 2016, 30, 7746-7754. [CrossRef]

8. Yao, Z.; Ma, X. Hydrothermal carbonization of Chinese fan palm. Bioresour. Technol. 2019, 282, 28-36. [CrossRef]

9. Parshetti, G.K.; Liu, Z.; Jain, A.; Srinivasan, M.P.; Balasubramanian, R. Hydrothermal carbonization of sewage sludge for energy production with coal. Fuel 2013, 111, 201-210. [CrossRef]

10. Yao, Z.; Ma, X.; Lin, Y. Effects of hydrothermal treatment temperature and residence time on characteristics and combustion behaviors of green waste. Appl. Therm. Eng. 2016, 104, 678-686. [CrossRef]

11. Yao, Z.; Ma, X.; Wang, Z.; Chen, L. Characteristics of co-combustion and kinetic study on hydrochar with oil shale: A thermogravimetric analysis. Appl. Therm. Eng. 2017, 110, 1420-1427. [CrossRef]

12. Chen, X.; Ma, X.; Peng, X.; Lin, Y.; Yao, Z. Conversion of sweet potato waste to solid fuel via hydrothermal carbonization. Bioresour. Technol. 2018, 249, 900-907. [CrossRef] [PubMed]

13. Bhatt, D.; Shrestha, A.; Dahal, R.; Acharya, B.; Basu, P.; MacEwen, R. Hydrothermal carbonization of biosolids from waste water treatment plant. Energies 2018, 11, 2286. [CrossRef]

14. Nizamuddin, S.; Baloch, H.A.; Griffin, G.J; Mubarak, N.M.; Bhutto, A.W.; Abro, R.; Mazari, S.A.; Ali, B.S. An overview of effect of process parameters on hydrothermal carbonization of biomass. Renew. Sustain. Energy Rev. 2017, 73, 1289-1299. [CrossRef]

15. Heilmann, S.M.; Jader, L.R.; Sadowsky, M.J.; Schendel, F.J.; Keitz, M.G.V.; Valentas, K.J. Hydrothermal carbonization of distiller's grains. Biomass Bioenergy 2011, 35, 2526-2533. [CrossRef]

16. Elaigwu, S.E.; Greenway, G.M. Microwave-assisted and conventional hydrothermal carbonization of lignocellulosic waste material: Comparison of the chemical and structural properties of the hydrochars. J. Anal. Appl. Pyrolysis 2016, 118, 1-8. [CrossRef] 
17. Sermyagina, E.; Saari, J.; Kaikko, J.; Vakkilainen, E. Hydrothermal carbonization of coniferous biomass: Effect of process parameters on mass and energy yields. J. Anal. Appl. Pyrolysis 2015, 113, 551-556. [CrossRef]

18. Kambo, H.S.; Dutta, A. Comparative evaluation of torrefaction and hydrothermal carbonization of lignocellulosic biomass for the production of solid biofuel. Energy Convers. Manag. 2015, 105, 746-755. [CrossRef]

19. Kim, D.; Lee, K.; Park, K.Y. Hydrothermal carbonization of anaerobically digested sludge for solid fuel production and energy recovery. Fuel 2014, 130, 120-125. [CrossRef]

20. Kim, D.; Lee, K.Y.; Park, K.Y. Upgrading the characteristics of biochar from cellulose, lignin, and xylan for solid biofuel production from biomass by hydrothermal carbonization. J. Ind. Eng. Chem. 2016, 42, 95-100. [CrossRef]

21. Kambo, H.S. Energy Densification of Lignocellulosic Biomass via Hydrothermal Carbonization and Torrefaction. Doctoral Dissertation, University of Guelph, Guelph, ON, Canada, 2014.

22. Byrappa, K.; Adschiri, T. Hydrothermal technology for nanotechnology. Prog. Cryst. Growth Charact. Mater. 2007, 53, 117-166. [CrossRef]

23. Funke, A. Hydrothermal carbonization of biomass: A summary and discussion of chemical mechanisms for process engineering. Biofuels Bioprod. Biorefining 2010, 4, 160-177. [CrossRef]

24. Liu, Z.; Balasubramanian, R. Upgrading of waste biomass by hydrothermal carbonization (HTC) and low temperature pyrolysis (LTP): A comparative evaluation. Appl. Energy 2014, 114, 857-864. [CrossRef]

25. Berge, N.D.; Ro, K.S.; Mao, J.; Flora, J.R.V.; Chappell, M.A.; Bae, S. Hydrothermal carbonization of municipal waste streams. Environ. Sci. Technol. 2011, 45, 5696-5703. [CrossRef] [PubMed]

26. Lu, X.; Pellechia, P.J.; Flora, J.R.; Berge, N.D. Influence of reaction time and temperature on product formation and characteristics associated with the hydrothermal carbonization of cellulose. Bioresour. Technol. 2013, 138, 180-190. [CrossRef]

27. Kang, S.; Li, X.; Fan, J.; Chang, J. Characterization of hydrochars produced by hydrothermal carbonization of lignin, cellulose, D-xylose, and wood meal. Ind. Eng. Chem. Res. 2012, 51, 9023-9031. [CrossRef]

28. Kim, D.; Yoshikawa, K.; Park, K. Characteristics of biochar obtained by hydrothermal carbonization of cellulose for renewable energy. Energies 2015, 8, 14040-14048. [CrossRef]

29. Kumar, S.; Loganathan, V.A.; Gupta, R.B.; Barnett, M.O. An assessment of U (VI) removal from groundwater using biochar produced from hydrothermal carbonization. J. Environ. Manag. 2011, 92, 2504-2512. [CrossRef]

30. Liu, C.; Huang, X.; Kong, L. Efficient low temperature hydrothermal carbonization of Chinese reed for biochar with high energy density. Energies 2017, 10, 2094. [CrossRef]

31. Song, C.; Zheng, H.; Shan, S.; Wu, S.; Wang, H.; Christie, P. Low-temperature hydrothermal carbonization of fresh pig manure: Effects of temperature on characteristics of hydrochars. J. Environ. Eng. 2019, 145, 04019029. [CrossRef]

32. Jayaramudu, J.; Agwuncha, S.; Ray, S.S.; Rajulu, A.V. Studies on the chemical resistance and mechnical properties of natural polyalthia cerasoides woven fabric/glass hybridized epoxy composites. Adv. Mater. Lett. 2015, 6, 114-119. [CrossRef]

33. Janković, B.; Manić, N.; Dodevski, V.; Radović, I.; Pijović, M.; Katnić, Đ.; Tasić, G. Physico-chemical characterization of carbonized apricot kernel shell as precursor for activated carbon preparation in clean technology utilization. J. Clean. Prod. 2019, 236, 117614. [CrossRef]

34. Sivasankarapillai, G.; McDonald, A.G. Synthesis and properties of lignin-highly branched poly (ester-amine) polymeric systems. Biomass Bioenergy 2011, 35, 919-931. [CrossRef]

35. Reza, M.T.; Uddin, M.H.; Lynam, J.G.; Hoekman, S.K.; Coronella, C.J. Hydrothermal carbonization of loblolly pine: Reaction chemistry and water balance. Biomass Convers. Biorefinery 2014, 4, 311-321. [CrossRef]

36. Liu, Z.; Quek, A.; Hoekman, S.K.; Balasubramanian, R. Production of solid biochar fuel from waste biomass by hydrothermal carbonization. Fuel 2013, 103, 943-949. [CrossRef]

37. Zhou, S.; Han, L.; Yang, Z.; Ma, Q. Influence of hydrothermal carbonization temperature on combustion characteristics of livestock and poultry manures. Trans. Chin. Soc. Agric. Eng. 2017, 33, 233-240.

(C) 2020 by the authors. Licensee MDPI, Basel, Switzerland. This article is an open access article distributed under the terms and conditions of the Creative Commons Attribution (CC BY) license (http://creativecommons.org/licenses/by/4.0/). 